\title{
Should Polytechnics Rely Solely on International Agents to Recruit International Students? A Case Study in New Zealand
}

\author{
Shaohua Yang ${ }^{1} \&$ M. Akhtaruzzaman ${ }^{1}$ \\ ${ }^{1}$ Faculty of Business, Information Technology \& Creative Arts, Toi Ohomai Institute of Technology, Rotorua, \\ New Zealand \\ Correspondence: Shaohua Yang, Master of Management, Faculty of Business, Information Technology \& \\ Creative Arts, Toi Ohomai Institute of Technology, Mokoia Drive, Tihiotonga, Rotorua, New Zealand. E-mail: \\ samuelyang0713@hotmail.com
}

Received: September 26, $2017 \quad$ Accepted: October 31, $2017 \quad$ Online Published: November 27, 2017

doi:10.5539/ijms.v9n6p14 URL: http://doi.org/10.5539/ijms.v9n6p14

\begin{abstract}
The aim of this paper is to investigate whether polytechnics should rely solely on international agents to recruit international students or not. To analyse the use of agents to recruit international students by tertiary institutions in New Zealand, this study attempts to find effectiveness and shortcomings of using international agents as a marketing strategy in recruiting international students. Though marketing strategies of marketing higher education is not new to the Anglo-Saxon countries (UK, US, and Australia), however, such marketing strategies of tertiary institutions in New Zealand have not been examined empirically. Deductive method of research was adopted and a total of 150 international students who studied at undergraduate and postgraduate level in a polytechnic in the Bay of Plenty in New Zealand participated in the research. The empirical findings of the research suggest that most international students relied on international agents for visa application and for enrolment process. A significant concern that a large proportion of the international students pointed to is the information mismatch between the promises by the agents and the reality that the international students faced here in New Zealand. It is suggested that relying solely on international agents to recruit international students might not be a sustainable marketing strategy for the tertiary institutions and other marketing strategies needs to be explored as well. Several policy implications in marketing strategy of higher education are also suggested in this study.
\end{abstract}

Keywords: international students, international agents, higher education marketing, polytechnics, recruiting international students

\section{Introduction and Background}

The market for exporting education service is highly competitive. Education providers in New Zealand are largely dependent on international agents to export education service to international students. New Zealand Government announced a target of $\$ 5$ billion earning by 2025 from exporting higher education 2025 (Joyce, 2016). There is no denying that New Zealand educational institutions have been very successful in achieving its objective on recruiting international students in this decade. It is credited to marketing strategies applied by education providers to grow the number of international students because higher education intuitions develop marketing strategies that can maintain a good number of international students (Nicolescu, 2009). In the UK, British Council stated that a growing number of institutions using agents as a part of their marketing strategy for the recruitment of international students was a "relatively new activity", and the Council sought to provide guidance in working with agents (Chang, 2003, p. 3). The use of international agents to recruit international students is, therefore, one of the effective marketing strategies.

In recent years, marketing strategies in recruiting international students have been widely studied in the AngloSaxon countries. Especially the debate on marketing strategy focusing on the use of international agents to recruit international students has been in the forefront of discussion and news (Kirsch, 2014). The existing literature suggests that the best practice for recruiting international students is to use international agents because agents have local connections, local knowledge and culture bridges (Reimo, Christine, \& Huang, n.d.). Other studies indicated that international agents were the main conduit for information, particularly for the communication with potential international students because they provide enquiry services regarding universities 
and student visa processes and assist in international student's enrolment (Kirsch, 2014; Hanover Research, 2010; Hagedorn \& Zhang, 2011; Morrish, 2011; Yang, \& Akhtaruzzaman, 2017). Aside from the above studies, Yang, Chen, \& Shen (2017) studied on the customer satisfaction with international student recruitment agencies applying face-to-face semi-structured interviews with international students in New Zealand. The results indicated that international students expect services offering such as effective information on programs and kiwi culture from their international agents (Yang, Chen, \& Shen, 2017). Scott (2014) found that international agents are important players in recruiting international students in the universities and a large proportion of international students are recruited by such agents (see Table 1). While it seems that there has been an increasing trend in the higher education institutions (HEIS) in recruiting international student through international recruitment agents, relatively little of the research have investigated the effectiveness and shortcomings of the use of international agents to recruit international student for HEIS in New Zealand. In New Zealand, with only a few reports revealing the adverse effects of the use of international agents in recruiting international students in polytechnics and private training schools (PTSs) (John, 2016; Phil, 2016; Bill 2016). In existing literature, it is not clear that if tertiary institutions in New Zealand should solely rely on international agents to recruit international students. Therefore, this research fills the gap and provides empirical evidence to enrich the body of academic literatures of marketing on higher education.

The primary aim of this study is to find out whether polytechnics should solely rely on international agents to recruit international students. Three specific research questions investigated in this research are (a)Why do international students choose to use international agents for their enrollments into polytechnics in New Zealand? (b) What knowledge or information regarding study polytechnic in New Zealand did international students expect to receive from the agents? (c) Do the agents provide reliable information to international students regarding studying, living and employment opportunities in New Zealand? Based on these research questions, finally this research examines if the sole dependency of the polytechnics on international agents for recruiting international students is a sustainable marketing strategy.

Table 1. Proportion of international students recruited by agents (2014)

\begin{tabular}{llll}
\hline Country & Percentage & Country & Percentage \\
\hline Australia & $53 \%$ & New Zealand & $47 \%$ \\
Canada & $41 \%$ & United Kingdom & $38 \%$ \\
United States & $11 \%$ & & \\
\hline
\end{tabular}

Source: From inside higher education.

\section{Theoretical Framework}

In higher education studies, agency theory remained largely unknown throughout 1980s and 1990s. Several researchers (e.g., Ferris, 1991; Hölttä, 1995; Williams, 1995; Massy, 1996; Geuna, 1999) did acknowledge the principal-agent settings in higher education, but in detail more systematic investigations of an agency relationship were left aside. It wasn't until 2000s that some scholars started applying the agency theory to investigate government-tertiary institution relationships (Kivistö, 2005, 2007; Lane, 2005, 2007; Lane \& Kivistö, 2008; Liefner, 2003). Currently, the context of the application of agency theory has been extended to cover a wide range of domains including leadership and strategic planning in higher education institutions (Auld, 2010), regulation and monitoring of international higher education (Borgos, 2013; Lane, Kinser, \& Knox, 2013) and university autonomy (Enders, de Boer \& Weyer, 2013). The application of agency theory in higher education studies defined principals and agents, as well as various degrees of agency relationship. Nonetheless, evidence testifying to the important role of agency theory when it comes to marketing strategy in higher education institutions is yet to be discovered. The strengths and weaknesses of the application of agents to marketing higher education need to be further analysed and discussed in a particular scope (polytechnics in New Zealand) by providing empirical evidence. To do so, this paper will provide delicate understanding of the process of using agents to recruit international students and experiences between agents and international students.

\section{Literature Review}

In literature concerning the marketing of higher education marketing strategy is always a contentious topic that can be identified in a very broad scope. Hence, this topic is worthy of continual exploration by scholars. Previous scholars have offered different perspectives on effective marketing strategies of recruitment of international students such as the use of agents, word of mouth, internet marketing and brand awareness (Hanover Research, 2010; Archer, 2010; Hagedorn \& Zhang, 2011; Archer \& Winters 2011; Allison, 2002; Zahra, 2013). Other 
scholars have investigated marketing strategies of higher education that had focused on three themes: segmentation, targeting and positioning (Hemsley-Brown \& Oplatka, 2006; Soutar \& Turner, 2002; Farr, 2003; Gray, Fam, \& Llanes, 2003).

Nevertheless, in recent years, the use of international agents as a marketing strategy for higher education in recruiting international students is a controversial topic and an emerging issue. Due to the large proportion of international students recruited by international agents, scholars have conducted further research through employing quantitative method based on descriptive research model. Quantitative data from universities in the English speaking countries (UK, US, Canada, Australia and New Zealand) collected international students' perspectives. For instance, there are a considerable number of studies that indicated higher education institutions should focus on the use of agents, and the results revealed that international students relied heavily on agents for enquiries regarding programme information and student visa processes (Hanover Research, 2010, Kirsch, 2014; Harris \& Rhall, 1993; Archer, 2010; Yang, \& Akhtaruzzaman, 2017).

In another case study, Hagedorn \& Zhang (2011) applied qualitative and quantitative research approaches. A large number of 257 students participated in their study and the result revealed that a significant number of international students lacked the knowledge of application and were confused about application process and needed additional inquiry services from their agents (Hagedorn \& Zhang, 2011). Furthermore, in a very recent study Yang \& Akhtaruzzaman (2017) adopted quantitative method to survey 140 international students in a polytechnic in New Zealand and the findings indicated that almost all international students needed assistance in student visa application from their international agents. In agreement with the above papers, other scholars also concluded that tertiary institutions were using agents as a valuable form of promotion of higher education to internal markets (Edwards \& Browne, 1991; Smart \& Ang, 1992; Harris \& Rhall, 1993). International agents did not comply with enrolment protocols of universities (Leo, 2008; Parr, 2014; Clare, 2015 John, 2016; Phil, 2016,) These studies did not provide empirical evidence as to shortcomings of international agents in recruiting international students for higher education institutions. This leaves a knowledge gap where research has not been conducted focusing on the strengths and weaknesses of the use of agents as a marketing strategy in recruiting international students for polytechnics in New Zealand context. To fill this gap this study looks into the question whether polytechnics should rely solely on international agents to recruit international students in New Zealand. To provide understandable concepts of the process of international students' recruiting in this study, Figure 1 (conceptual framework) demonstrates the relationship between New Zealand Polytechnics, international agents and international students.

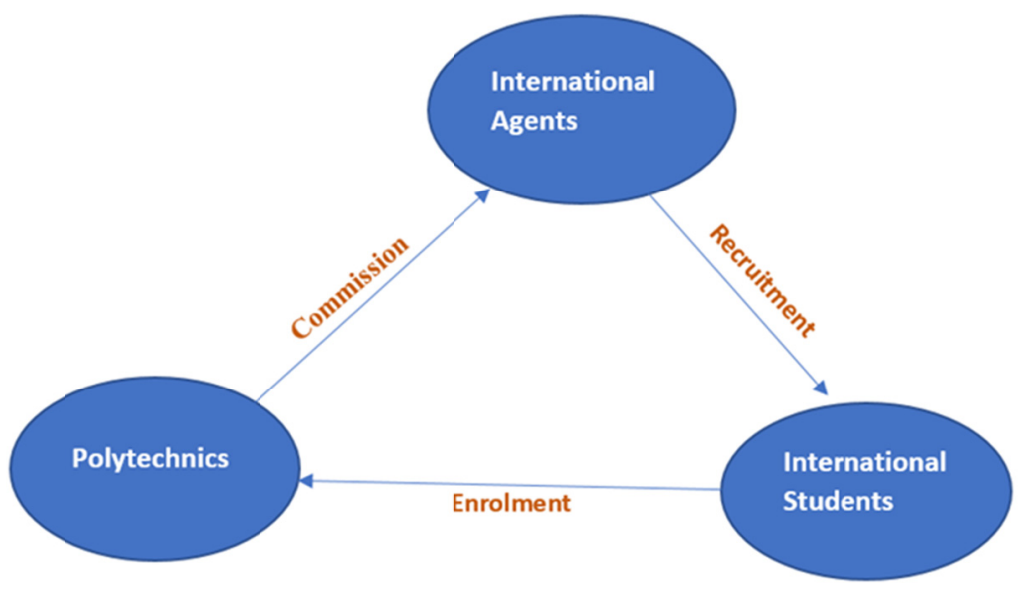

Figure 1. Conceptual framework

\section{Research Method}

The aim of a research method is to minimise the likelihood of errors and to reduce ambiguity of evidence. Research approaches offer informed options and are practical guidelines for the overall configuration of research (Saunders, Lewis, \& Thornhill, 2005). There are two different types of approaches: deductive approach and inductive approach; this study applies a deductive approach because quantitative research was utilised.

Research design needs to define the nature of the implemented methodology, as well as the spatial location, 
industry and analytical components selected. The three types of research designs are exploratory, descriptive and causal research. Matching the particular decision situation with a suitable type of research is crucial to developing useful research results (Zikmund, Babin, Carr, \& Griffin, 2012). Among the three, descriptive research is the most suitable one to apply in this study for it describes characteristics of objects, people, groups and organisations. The research design is based on a descriptive research model typically used for survey based research. Finally, the researcher presents a valid personal or school identification to all respondents for ethical reasons.

The study used survey methods for the quantitative research (Saunders, Lewis, \& Thornhill, 2009). To conduct quantitative style, questionnaires were the research instrument. The items in questionnaire have been revised following previous original literatures (e.g., Kirsch 2014; Hanover Research, 2010; Hagedorn \& Zhang, 2010; Emily, 2014; Harris \& Rhall, 1993; Archer, 2010; Leo, 2008; Parr, 2014; Clare, 2015; John, 2016; Phil, 2016) and based on the purpose of this research.

The sample of this study is comprised of international students studying at one polytechnic in Bay of Plenty. For data collection, 150 international students were selected through random sampling method. The researcher conducted the survey mainly by attending each cohort with permission from lecturers. All responders in the cohorts were requested to complete a questionnaire. Subsequently, 140 international students completed and returned their questionnaires. To investigate how international students had been recruited by their agents for the Polytechnic, eight questions were included in the questionnaire. The questions in the questionnaire were answered by the five Likert scales ranging from 1 -- strongly agree to 5 -- strongly disagree

Moreover, the demographic part of the questionnaire included gender, ages, nationality, and level of education of the participants. The details of respondent's background are shown in Table 2. Different statistical techniques for descriptive statistic (descriptive, frequencies, crosstab and multiple answers frequency) were used to answer different types of research questions of this study.

\section{Findings and Discussion}

\subsection{Participants' Profile}

As noted above a total of 150 participants (140 participants completed questionnaires) were involved in this study. Table 2 demonstrates a summary of the demographic characteristics of the participants, which turned out to be $37.9 \%$ female and $62.1 \%$ male. There were 9 different nationalities of participants, the majority of the participants $(50 \%)$ from Indian. This indicated that for New Zealand higher education, Indian market is the largest compared to other international markets whereas Pilipino (37.9\%) was the second. In contrast, the lowest percentages of participants were Burmese, Thai and Indonesian. Additionally, regarding participants' education, most international students (37.9\%) had acquired postgraduate diplomas and a fraction of $0.7 \%$ had only studied foundation course. The second largest percentage of participants $(28.6 \%)$ had obtained diplomas.

Table 2. Demographic profile $(\mathrm{N}=140)$

\begin{tabular}{llll}
\hline & & Frequency & Percentage \\
\hline Gender & Female & 53 & 37.9 \\
& Male & 87 & 62.1 \\
\hline Nationality & Chinese & 7 & 5.0 \\
& Indian & 70 & 50.0 \\
& Filipino & 53 & 37.9 \\
& Bangladeshi & 2 & 1.4 \\
Nepalese & 4 & 2.9 \\
& Chilian & 1 & .7 \\
& Indonesian & 1 & .7 \\
& Thai & 1 & .7 \\
& Burmese & 1 & .7 \\
\hline Program of study & English & 6 & 4.3 \\
& Foundation & 1 & .7 \\
& Diploma & 40 & 28.6 \\
& Graduate Diploma & 28 & 20.0 \\
& Bachelors' Degree & 3 & 2.1 \\
& Postgraduate Diploma & 53 & 37.9 \\
& Master's Degree & 9 & 6.4 \\
\hline
\end{tabular}


Table 3. The use of International Agents $(\mathrm{N}=140)$

\begin{tabular}{|c|c|c|c|}
\hline Questions (Items) & & Frequency & Percentage \\
\hline \multirow{5}{*}{$\begin{array}{l}\text { (1) It is better for international students to use an agent } \\
\text { rather than applying directly to New Zealand } \\
\text { polytechnics. }\end{array}$} & Strongly Disagree & 12 & 8.6 \\
\hline & Disagree & 22 & 15.7 \\
\hline & Neutral & 34 & 24.3 \\
\hline & Agree & 62 & 44.3 \\
\hline & Strongly Agree & 10 & 7.1 \\
\hline \multirow{5}{*}{$\begin{array}{l}\text { (2) International agents can offer clear information (for } \\
\text { example, regarding costs of study immigration policies, } \\
\text { the student visa process and program information). }\end{array}$} & Strongly Disagree & 26 & 18.6 \\
\hline & Disagree & 23 & 16.4 \\
\hline & Neutral & 35 & 25.0 \\
\hline & Agree & 45 & 32.1 \\
\hline & Strongly Agree & 11 & 7.9 \\
\hline \multirow{5}{*}{$\begin{array}{l}\text { (3) International agents are helpful in assisting with } \\
\text { student visa applications }\end{array}$} & Strongly Disagree & 8 & 5.7 \\
\hline & Disagree & 10 & 7.1 \\
\hline & Neutral & 30 & 21.4 \\
\hline & Agree & 76 & 54.3 \\
\hline & Strongly Agree & 16 & 11.4 \\
\hline \multirow{5}{*}{$\begin{array}{l}\text { (4) Agents give misleading information and promises with } \\
\text { regards to employment opportunities in New Zealand. }\end{array}$} & Strongly Disagree & 11 & 7.9 \\
\hline & Disagree & 11 & 7.9 \\
\hline & Neutral & 26 & 18.6 \\
\hline & Agree & 53 & 37.9 \\
\hline & Strongly Agree & 39 & 27.9 \\
\hline \multirow{5}{*}{$\begin{array}{l}\text { (5) International agents have a significant influence when } \\
\text { it comes to your choice of polytechnic. }\end{array}$} & Strongly Disagree & 2 & 1.4 \\
\hline & Disagree & 17 & 12.1 \\
\hline & Neutral & 24 & 17.1 \\
\hline & Agree & 76 & 54.3 \\
\hline & Strongly Agree & 21 & 15.0 \\
\hline \multirow{5}{*}{$\begin{array}{l}\text { (6) If you were asked by family or friends about higher } \\
\text { study in a NZ tertiary institute, you would recommend } \\
\text { using international agents. }\end{array}$} & Strongly Disagree & 12 & 8.6 \\
\hline & Disagree & 29 & 20.7 \\
\hline & Neutral & 41 & 29.3 \\
\hline & Agree & 49 & 35.0 \\
\hline & Strongly Agree & 9 & 6.4 \\
\hline \multirow{4}{*}{$\begin{array}{l}\text { (7) Academic experiences in New Zealand are similar to } \\
\text { what the agent told you, before you left your home } \\
\text { country. }\end{array}$} & Strongly Disagree & 25 & 17.9 \\
\hline & Disagree & 40 & 28.6 \\
\hline & Neutral & 35 & 25.0 \\
\hline & Agree & 32 & 22.9 \\
\hline \multirow{6}{*}{$\begin{array}{l}\text { (8) The service of the agent for the enrolment process is } \\
\text { really helpful and effective. }\end{array}$} & Strongly Agree & 8 & 5.7 \\
\hline & Strongly Disagree & 13 & 9.3 \\
\hline & Disagree & 19 & 13.6 \\
\hline & Neutral & 36 & 25.7 \\
\hline & Agree & 57 & 40.7 \\
\hline & Strongly Agree & 15 & 10.7 \\
\hline
\end{tabular}

It can be seen from the results of survey that the above mentioned three research questions were answered in this study. There were 8 questions (items) in Table 3 and the results were analysed using this table. Three sections were proposed in this discussion following the research questions. In comparison with previous studies, a discussion is given to support the findings to the research questions.

$R Q$ (a): Why do international students choose to use international agents for their enrollments into polytechnics in New Zealand?

As seen in item 1 in Table 3, 44.3\% of the respondents agreed that international students preferred to apply for the polytechnic through international agents. However, there are still $15.7 \%$ of the respondents disagreeing that international students tended to use international agents to apply for the polytechnic. In item 3 , the highest percentage $(54.3 \%)$ of the respondents agreed that agents were helpful in assisting with student visa applications. Item 5 indicates that more than half of the surveyed international students were influenced by international agents when they made a decision on the choice of polytechnics. In item $8,40.7 \%$ of the respondents agreed that the service of the agents for the enrolment process was helpful and effective. It is clear that international agents play a significant role in recruiting international students Results of this survey is similar to previous studies claiming that international students lacked the knowledge of application and needed to rely heavily on agents for 
guidance of student visa application and enrolment process (Hagedorn \& Zhang, 2011; Hanover Research, 2010; Kirsch, 2014; Harris \& Rhall, 1993; Archer, 2010). Therefore, international students want to work with their agents because they need information of overseas study applications and the guidance of polytechnic selection.

$R Q$ (b): What knowledge or information regarding study polytechnic in New Zealand did international students expect to receive from the agency?

Based on the results from Table 3, item 2 revealed that $32.1 \%$ of the respondents agreed that international agents offered clear information regarding the costs of study immigration policies, the student visa process and program information. However, a considerable proportion of the respondents $(25.0 \%)$ claimed that international students were not sure whether agents could offer clear information or not. Only $18.6 \%$ of the respondents disagreed with above statement (item 2), suggesting that almost one-fifth of the international students found that the agents did not provide clear information regarding visa application and program information and costs of study. Moreover, in item 8, 40.7\% agreed that service of the agents for the enrolment process was helpful and effective. These results are also compatible with previous studies, with literature suggesting that international student needed knowledge of application process and particular information of visa application (Hagedorn \& Zhang, 2011; Kirsch, 2014; Harris \& Rhall, 1993; Archer, 2010). Thus, the top source of information and knowledge (e.g., enrolment process, polytechnic selection, visa application and program information) that international students expect to receive is their agents.

$R Q(c)$ : Do the agents provide reliable information to international students regarding studying, living and employment opportunities in New Zealand?

It can be seen in Table 3, as for item 4,37.9\% of the respondents agreed that agents gave misleading information and promises with regards to employment opportunities in New Zealand. Additionally, $27.9 \%$ strongly agreed with the above statement. It suggests there is a mismatch between what they were told by their agents and what they are facing in terms of living and employment opportunities in New Zealand. The question in item 6 has an important implication for sustainability of future growth of education export and suggests that only $35 \%$ of the respondents agreed that they will recommend their friends and family for higher studies in New Zealand. This is a clear message that experiences of a significant number of international students are not as satisfactory as we thought and things around the issues must be improved to attract international students in the future. In item 7, a high percentage $(28.6 \%)$ of respondents disagreed that academic experiences in New Zealand were similar to what agents told them, before they left their home countries. Surprisingly, this result is similar to previous research findings (e.g., John, 2016; Phil, 2016; Bill, 2016) which indicated that international agents on behalf of polytechnics and PTSs to recruit Indian international students offered misleading information/false promise to Indian international students. Consequently, combined with previous report, results of this survey of polytechnic revealed the concept that agents do not provide reliable information to international students regarding study, living and employment opportunities in New Zealand.

In summary, the findings of this study revealed that polytechnics in New Zealand use international agents in recruiting international students as an effective market strategy. Polytechnics working together with international agents would achieve a high number of enrolments. International agents are familiar with their home countries' market while grasping local connections, local knowledge and culture bridges in hands (Reimo, Christine, \& Huang. n.d). From the international students' perspectives, they need to rely on international agents for visa application and enrolment process (Hagedorn \& Zhang, 2011). Most international students lack the knowledge as to how to apply for study in New Zealand. Although the use of international agents in recruiting international students for polytechnics is an effective strategy, there are still several issues by which polytechnics' image and reputation may be damaged in the future. The result of this study also demonstrated that international agents provided international students with misleading information and promises regarding employment opportunities in New Zealand. Therefore, polytechnics relying solely on international agents to recruit international students might not be a sustainable marketing strategy. It is better to detail the code of conduct for the international agents and to monitor intensively whether they are strictly followed by the international agents. International agents should only provide information related to study and visa process and restrict them from giving any promises regarding employment in New Zealand which is beyond their scope.

\section{Implication and Limitation}

Although, international agents play a crucial role in their home countries' market, there are still some worries that international students may had bad experiences with unethical agents. International agents are third parties locating in their home countries. Polytechnics only can give agents the authorization and pay them based on commission. It is suggested that polytechnics need to continue to develop new quality and professional agents. 
All new agents should be selected and trained carefully. Monitoring, enforcement and rewarding the top or quality agents is also a part of polytechnics-agent relationships/trusted building. Get close to international agents in order to push them to be more professional in providing service to international students. In addition, when polytechnics start to issue the contract with new international agents, the agents' background and affiliation need to be evaluated as well. Ideally, Polytechnics can target potential internationals agents who are equipped with overseas qualifications. In recent years, many overseas returning students seeks opportunities in the education consultancy industry and some have become international agents. Raimo, Christine, \& Huang (n.d.) indicated that to better understand trust-worthy and quality agents, polytechnic-agent relationship can be viewed as a virtuous circle such as applicants, universities/polytechnics, alumni and agents (see Figure 1). This forms a virtuous circle of trust and quality that would produce quality agents and a trustworthy relationship between international students, polytechnics and international agents. There is another possible suggestion that polytechnics could also establish the process of agents' performance review based on the survey of international students' satisfaction when they arrive and enrol in courses in New Zealand. If international agents carry out poor performance, polytechnics may terminate the contracts with the agents.



Figure 1. Virtuous circle

Source: Raimo, Christine, \& Huang, n.d.

The findings of this study contribute to literature of the kind in several ways. Firstly, the research findings revealed the strengths and weaknesses of the use of international agents as a marketing strategy in recruiting internationals students for polytechnics. The findings will also contribute to a better understanding of the process of recruiting international students via agents. It also helps to provide a good understanding of selecting quality international agents for polytechnics and international students as well. Secondly, there is still a lack of academic literature of marketing strategies in recruiting international students in New Zealand context except a limited number of studies (e.g., Yang, \& Akhtaruzzaman, 2017; John, 2016; Phil, 2016; Bill 2016). This study contributes to enlarging the body of literature of higher education marketing strategies by applying quantitative approach of research.

Although this study investigates particular marketing strategy (the use of international agents) in New Zealand and provides delicate insights for international students recruiting, a few limitations still can be found. There must be other alternative market strategies that can achieve a good outcome for enrolment in polytechnics in New Zealand. Further research may focus on the marketing of higher education and this could expand knowledge on international students' recruitment. In regards to methodology, a larger sample size could have been carried out to get a more precise idea to create more effective marketing strategies. Further studies using a bigger sample size and including more polytechnics and/or universities would add to the generalizability of the findings.

\section{References}

Auld, D. (2010). Strategic planning and the principal-agent issue in higher education leadership. Academic Leadership, 8(3), 31-35. Retrieved from Business Source Complete database.

Allison, N. (2002). The higher education institution website as a marketing tool in student recruitment. Retrieved from http://umpalumpa.info/webmarketing/HE_web_marketing.doc 
Archer, W. (2010). The i-graduate ICEF Agent Barometer. Paper presented at the ICEF Berlin Workshop, Berlin, Germany. Retrieved from http://www.anzaworkshopcom/fileadmin/user_upload/2011/igraduate_ICEF_Agent_Barometer_2010.pdf

Archer, W., \& Winters, J. (2011). Global perspectives of challenges to the international student recruitment and enrolment experience. Paper presented at the Annual European Association for International Education Conference, Copenhagen, Germany

Bill, M. (2016). Nelson mail. NMIT dumps Indian agency after threats to student. Retrieved from http://www.stuff.co.nz/nelson-mail/news/67650504/nmit-dumps-indian-agency-after-threats-to-student

Borgos, J. (2013). Using principal-agent theory as a framework for analysis in evaluating the multiple stakeholders involved in the accreditation and quality assurance of international medical branch campuses. Quality in Higher Education, 19(2), 173-190. http://dx.doi.org/10.1080/13538322.2013.805068

Chang, C. (2003). Recruitment agents: a legal overview. British Council. Retrieved from http://www.britishcouncil.org/recruitment_agents_-_a_legal_overview.pdf

Clare, C. (2015). International student recruitment agency used by Australian National University willing to accept forged transcripts. Retrieved from http://www.canberratimes.com.au/act-news/international-student-recruitment-agency-used-by-australian-nat ional-university-willing-to-accept-forged-transcripts-20150421-1 mpsup.html

Edwards, S., \& Browne, M. (1991), Destination Australia: Pre-departure needs of temporary residents and immigrants. Bureau of Immigration Research. Canberra, Australia.

Enders, J., de Boer, H., \& Weyer, E. (2013). Regulatory autonomy and performance: The reform of higher education revisited. Higher Education, 65, 5-23. https://doi.org/10.1007/s10734-012-9578-4

Farr, M. (2003). Extending participation in higher education -implications for marketing. Journal of Targeting Measurement and Analysis for Marketing, 11(4), 314-325. https://doi.org/10.1057/palgrave.jt.5740087

Ferris, J. M. (1991). Contracting and higher education. The Journal of Higher Education, 62(1), 1-24. https://doi.org/10.1080/00221546.1991.11774103

Gray, B. J., Fam, K., \& Llanes, V. A. (2003). Branding universities in Asian markets. Journal of product \& brand management, 12(2), 108-120. https://doi.org/10.1108/10610420310469797

Geuna, A. (1999). The Economics of Knowledge Production: Funding and Structure of University research. Cheltenham: Edward Elgar.

Hagedorn, L., \& Zhang, L. Y. (2011). The use of agents in recruiting Chinese undergraduates. Journal of Studies in International Education, 15(2), 186-202. https://doi.org/10.1177/1028315310385460

Hölttä, S. (1995). Towards the Self-Regulative University (Doctoral dissertation). Joensuu: University of Joensuu.

Hanover Research. (2010). Best practices in international student recruitment and retention in Anglophone countries. $\quad$ Retrieved from http://www.hanoverresearch.com/wp-content/uploads/2011/12/Best-Practices-in-International-Student-Recr uitment-and-Retention-in-Anglophone-Countries-Membership.pdf

Harris, D. R., \& Rhall, T. M. (1993). Survey of international students. Department of Employment Education and Training, Canberra, Australia: Braddon.

Hemsley-Brown, J., \& Oplatka, I. (2006). Universities in a competitive global marketplace: a systematic review of the literature on higher education marketing. International Journal of Public Sector Management, 19(4), 316-338. https://doi.org/10.1108/09513550610669176

John, W. (2016). The dominion post. Warning of “education trafficking” scams hitting New Zealand. Retrieved from http://www.stuff.co.nz/dominion-post/76742569/warning-of-education-trafficking-scams-hitting-new-zeala nd

Joyce, H. S. (2016) New Zealand Nation Party: International education worth $\$ 4.28$ billion. Retrieved from https://www.national.org.nz/news/2016-11-08-international-education-worth-4-28-billion

Kirsch, M. (2014). The use of agents in international student recruitment: International education professional's opinions. Capstone Collection. 2635. Retrieved from http://digitalcollections.sit.edu/capstones/2635 
Kivistö, J. (2005). Government-higher education institution relationship: Theoretical considerations from the perspective of agency theory. Tertiary Education and Management, 11(1), 1-17. http://dx.doi.org/10.1080/13583883.2005.9967136

Kivistö, J. (2007) Agency Theory as a Framework for the Government-University Relationship (Doctoral dissertation). Tampere: Tampere University Press.

Leo, C. (2010). Education agents: Friend and foe for university recruiters. Retrieved from http://www.universityaffairs.ca/news/news-article/education-agents/

Lane, J. E. (2005). Agency Problems with Complex Principals: State Oversight of Higher Education: A Theoretical Review of Agency Problems with Complex Principals, Paper presented at the annual conference of the Association for the Study of Higher Education (Philadelphia, United States).

Lane, J. E., Kinser, K., \& Knox, D. (2013). Regulating cross-border higher education: A case study of the United States. Higher Education Policy, 26, 147-172. https://doi.org/10.1057/hep.2012.23

Lane, J. E. (2007). Spider web of oversight: Latent and manifest regulatory controls in higher education. Journal of Higher Education, 78(6), 1-30.

Lane, J. E., \& Kivistö, J. (2008). Interests, information, and incentives in higher education: Principal-agent theory and its potential applications to the study of higher education governance. In J. C. Smart (Ed.), Higher education: Handbook of Theory and Research (pp. 141-179). Dordrecht: Springer. https://doi.org/10.1007/978-1-4020-6959-8_5

Liefner, I. (2003). Funding, resource allocation, and performance in higher education Systems. Higher Education, 46, 469-489. https://doi.org/10.1023/A:1027381906977

Morrish, S. C., \& Lee, C. (2011). Country of origin as a source of sustainable competitive advantage: The case for international higher education institutions in New Zealand. Journal of Strategic Marketing, 19(6), 517-529. http://dx.doi.org/10.1080/0965254X.2011.599497

Massy, W. F. (1996). Reengineering resource allocation systems. In W. F. Massy (Ed.), Resource Allocation in Higher Education (pp. 15-47). Ann Arbor: The University of Michigan Press. https://doi.org/10.3998/mpub.14347

Nicolescu, L. (2009). Applying marketing to higher education: Scope and limits. Management Marketing, 4(2), 35-44. Retrieved from Business Source Complete database.

Parr, C. (2014). Student recruitment agents sometimes engage in "outright fraud". Retrieved from $\mathrm{http}: / / \mathrm{www} . t i m e s h i g h e r e d u c a t i o n . c o . u k / n e w s /$ student-recruitment-agents-sometimes-engage-in-outright-fra ud/2015573.article

Paul, G. (2017). Northland export education strategy launched. Retrieved from https://www.beehive.govt.nz/release/northland-export-education-strategy-launched

Phil, P. (2016). Indian student visa fraud numbers snowball. Retrieved from http://www.radionz.co.nz/news/national/316173/indian-student-visa-fraud-numbers-snowball

Raimo, I., Christine, H., \& Huang, Y. (n.d.). Managing international student recruitment agents. Retrieved from https://www.britishcouncil.org/sites/default/files/managing_education_agents_report_for_bc_2.pdf

Saunders, M., Lewis, P., \& Thornhill, A. (2005). Research methods for business students (4th ed). London, United Kingdom: Prentice Hall.

Saunders, M., Lewis, P., \& Thornhill, A. (2009). Research methods for business students (5th ed.). Essex, England: Pearson Education.

Scott, J. (2014). Inside higher education. The agent impact. Retrieved from https://www.insidehighered.com/news/2014/05/01/new-data-use-agents-recruit-international-students

Smart, D., \& Ang, G. (1992). Medium term market opportunities for Australian higher education: A Pilot Survey of Singapore Policy. Perth, Australia: Asia Research Centre.

Soutar, G. N., \& Turner, J. P (2002). Students' preferences for university: a conjoint analysis. Williams, G. (1995). The marketization of higher education: Reforms and potential reforms in higher education finance. In D. D. Dill \& B. Sporn (Eds.), Emerging Patterns of Social Demand and University Reform: Through a Glass Darkly (pp. 170-193). Oxford: IAU Press/Pergamon.

Williams, G. (1995). The marketization of higher education: Reforms and potential reforms in higher education 
finance. In D. D. Dill \& B. Sporn (Eds.), Emerging Patterns of Social Demand and University Reform: Through a Glass Darkly (pp. 170-193). Oxford: IAU Press/Pergamon.

Yang, S., Chen, X., \& Shen, X. (2017). An exploratory study of customer satisfaction with international student recruitment agencies: a case study in New Zealand. International Journal of Business and Management, 12(11), 130-140. https://doi.org/10.5539/ijbm.v12n11p130

Yang, S., \& Akhtaruzzaman, M. (2017). Effective marketing techniques in recruiting international students: evidence from a tertiary institute in New Zealand. Journal of Engineering and Applied Sciences, 12(2), 336-352.

Zahra, Q. (2013). Higher education marketing: Awareness and reputation. Retrieved from http://aha.elliance.com/2013/07/29/higher-education-marketing-awareness-and-reputation/

Zikmund, W., Babin, B., Carr, J., \& Griffin, M. (2012). Business research methods (9th ed.). Mason, OH: South Western.

\section{Copyrights}

Copyright for this article is retained by the author, with first publication rights granted to the journal.

This is an open-access article distributed under the terms and conditions of the Creative Commons Attribution license (http://creativecommons.org/licenses/by/4.0/). 